conciencia de lo que es mejor y la dignidad y seriedad del menester lírico. Rehuye lo fácil, aunque a menudo sin éxito, y notamos en él el gusto apasionado-que lo dignifica-por el obstáculo de que hablaba Baudelaire.

Si intentáramos definir-ocupación tan desagradable que acaso estamos desempeñando, tal vez sin desearlola poesía de Verdié, diríamos que es un producto híbrido de la objetividad y la subjetividad, porque estos dos factores co-existen, con más extensión el objetivo, en Adótico cielo: pero la subjetividad debemos entenderla en su significación más elemental y frecuente (no en aquella que tan bien precisara un escritor europeo al llamar subjetivismo el destino misterioso en virtud del cual un sujeto lo primero y más evidente que halla en el mundo es a sí mismo). En Verdié lo subjetivo no es innato sino cualidad adquirida $y$, como buen meridional, recurro nuevamente al escritor recién citado:

antes de percibir su $y o$, y con superior evidencia, le son presentes el $t u ́$ y el êl, los demás hombres, el árbol, el mar, la estrella.

Por eso en su libro no encontramos esa cálida intimidad, esa sensación de soledad, esa ingénita pasión introvertida, característica de los individuos de vitalidad endógena, es decir, de los individuos subjetivos. Este dominio de lo subjetivo es, por lo demás, peculiar a la mayoría de los nuevos líricos uruguayos.

Un escritor español, no deseamos nombrarlo, dijo hablando de poesía indo-hispâniç (yo voy a suponer la existencia de una poesía indo-hispánica o latino-americana, como quiera llamársele, lo mismo que la francesa por ejemplo; es decir, expresión en un mismo idioma de un conjunto de sensibilidades diferentes pero de un valor representativo más o menos idéntico en su significación dentro del mundo estético); manifestaba sus preferencias por la poesía del Uruguay, México y Argentina, debido a su diafanidad meridional, posponiendo la de Chile, por su obscuridad. Debo hacer presente que esta referencia ha sido hecha por la poesía que es costumbre llamar nueva (2).

¿Por qué llamar obscura a la poesía chilena? Es claro que para los individuos de contacto lírico no frecuente puede serlo, como para los que carecen de la capacidad de percepción poética. ¿Por qué no llamarla mejor, esencialmente subjetiva, un tanto misteriosa, esotérica si se quiere? En cuanto a la poesía de los países nombrados con prioridad es, sin duda, más objetiva. De ahí su diafanidad que a veces es fotografia o simplicidad. Sin olvidar, se entiende, las infaltables excepciones, creemos que esa es su característica. Podríamos comprobarlo pero nos extenderíamos demasiado.

Desde luego Adótico cielo puede ser un ejemplo.-Arturo Troncoso.

\section{GleBA, por Max Jiménez.}

Después de haber leído Gleba (1) casi nos asombramos al comprobar

(2) Escribo sólo en forma interina poesía <nueva', pues algún día deberé insistir sobre ella.

(1) Editorial Le livre libre, París. 
que en estos tiempos y en París se editen todavía obras de esta especie. Casi, pues hoy día ya no es posible asombrarse de nada-tan inveterado $y$ permanente se ha hecho el asombro que ha llegado a perder su cualidad de tal-. Nisiquiera ante un libro de versos tan indigentes como Gleba ni ante la audacia que significa publicarlo.

Max Jiménez-nativo de Costa Rica-inicia su libro con un pequeño introito:

Un prólogo (unas líneas de compromiso), dado por algún pontífice del buen decir, será muleta que bien poco disimule la cojera de mis versos. Prefiero cojear solo, abrigando la ci eencia de que ya en este siglo no se ha de seguir dando al público la categoría de rebaño, poniendo a su cuidado un buen pastor, que muestre cuál es la cizaña y cuál el trigo. Mi técvica y mis aspiraciones se explican por el título Gleba: remover la tierra del pasado y dejar caer en ella la propia semilla, que, aunque humilde, abriga la esperanza de dar una cosecha en el futuro.

Son palabras sensatas, modestas que incitan al silencio. Pero.... En el primer poema (llamémoslo así) nuestra buena intención inicial desaparece frente a la jactancia del autor:

Pasad por mi jardín sombrero en y si al final lleváis sensualidad, (mano es porque allí está el poeta más huy más grande que vió la eternidad. (mano

Esta jactancia nada tendría de extraña-es sabido que el literato es uno de los seres que la padecen más intensa-si hubiera alguna resonan- cia de lo que dicen esos versos aunque muy lejanamente aproximada, en el resto de la obra; pero Gleba es tan vulgar que difícilmente pueda existir otro libro de versos más malos que el de Jiménez, publicado en estos últimos años. Vamcs a probarlo con dos o tres ejemplos tomados al azar.

En la composición titulada San Juan el Bautista dice:

Supo el Señor que en Palestina ya se impartía agua divina.

Y fué en aguas del Jordán donde Jesús encontró a Juan.

Al oír del Redentor el sagrado deseo salió de sus labios humilde balbuceo.

«Señor-dijo el Baustista, azora(do-: yo soy el que por Ti debe ser bauti(zado.s

En otra composición:

Si sólo fuera un sueño... $Y$ al fin de la jornada

la venda del pasado quitáramos del ceño y viérese aclarado el enigma de lo creado.

Basta. Podriamos llenar varıas páginas de Atenea con versos semejantes. A pesar de lo ingenuo que es manifestarlo, no se crea en nosotros una intención premeditada al juzgar con acritud este libro. Casi con ahinco hemos buscado una estrofa, un verso siquiera donde pudiéramos atisbarel hervor de una personalidad. Con ahinco y con cier to egoísmo para justificar también la lectura de estos cincuenta y cuatro poemas-hemos tenido la paciencia de contarlos-con algún breve goce estético.

Por ahí dice Jiménez; 
En la casa (tono familiar):

Este muchacho siempre pensando y escribiendo disparates.

Sin embargo sus familiares están equivocados, pues Jiménez no piensa ni tampoco escribe disparates, sino tonterías. El disparate-se sabe-es siempre divertido, sugeridor de la sonrisa, del amable regocijo, mien tras que la tontería es triste y produce compasión, aún en los individuos más anticristianos. Y después de la lectura de Gleba, hemos tenido que compadecer a su autor, muy a pesar nuestro, por una imperiosa necesidad justificativa.-Arturo Troncoso.

\section{ESTUDIOS SEXUALES}

El SEXO EN LA CIVILIZACIÓN, por varios autores, reunido por $V . F$. Carlverton y S. D. Schmalhausen.

Alguien, creo que un autor francés, ha dicho que el mundo moderno vive en plena edad media sexual. Ha querido decir con esto, seguramente, que el mundo lucha en estos momentos por llegar a una fijación exacta del problema sexual, de la conducta sexual, de la definición sexual. La biología sexual constituye hoy día uno de los más apasionantes temas científicos y ha dado margen a creaciones maravillosas de la inteligencia humana. Fuera de la biología el interés no es menor. El sexo abarca casi todos los campos de la actividad humana y sus relaciones son infinitas; todo cabe en ellas, desde las creaciones artísticas hasta los ritos religiosos. Poco a poco se descubren nuevas vetas y se fijan nuevas características, características morales, intelectuales, fisiológicas, que identifican al individuo dentro de tal o cual rama sexual.

Este libro contiene treinta ensayos de autpres diversos, en su mayoría de nacionalidad americana, y está dedicado ea esas mujeres que tomaron parte en la lucha por la emancipación del sexo y por una civilización mejor '. Esas mujeres son: Mary Wollstonecraft, Jorge Sand, Ellen Key, Oliva Schreiner, Lilli Braun, Isadora Duncan, Aletia Jacobs, Alejandra Kollontay, María Stopes y Dora Russell. Hay entre ellas doctoras como María Stopes, bailarinas, como Isadora Duncan, y educacionistas, como Ellen Key; escritoras, como Jorge Sand, y revolucionarias comunistas, como Alejandra Kollontay, mujęres todas que han sobresalido, con sus obras y con sus vidas, de la masa femenina y que han contribuido a crear para la mujer una norma espiritual nueva.

Principia el libro con un ensayo de Roberto Briffault sobre El sexo cn la religión y termina con otro de Roberto Morss Lovett, sobre El sexo y la novela. Arturo Davison Ficke escribe un interesante estudio sobre la poesía sexual, tema novísimo, con citas de autores norteamericanos e ingleses, que demuestran el lento proceso de desarrollo de la poesía amorosa, desarrollo que está directamente influenciada por las ideas sexuales reinantes en cada época literaria.

El total del libro está dividido en 